\title{
O Direito Penal do Inimigo como Quebra do ESTADO DE DiREITO: A NORMALIZAÇÃO DO ESTADO DE EXCEÇÃO
}

\author{
André Luís Callegari* \\ Raul Marques Linhares**
}

\begin{abstract}
1 Introdução. $2 \mathrm{O}$ Estado de Direito. $3 \mathrm{O}$ direito penal do inimigo: quebra do Es-
\end{abstract} tado de Direito e normalização do Estado de Exceção. 4 Conclusão. Referências.

\section{RESUMO}

O Estado de Direito é considerado como uma barreira não só formal, mas também material do exercício do poder do Estado, como verdadeira proteção aos direitos e às garantias dos cidadãos. Em relação ao Direito Penal, essa barreira se faz ainda mais importante, considerando-se o perigo dos excessos na aplicação do poder punitivo do Estado. Contudo, algumas propostas doutrinárias se colocam em possível contradição com a lógica da criação de barreiras ao exercício do poder do Estado de Direito, o que acontece com o Direito Penal do inimigo. Por isso, o presente trabalho pretende desenvolver os postulados básicos do Estado de Direito, contrapondo-o ao Estado de exceção, concluindo pela incompatibilidade do Direito Penal do inimigo com esse modelo de Estado. Para tanto, utilizar-se-á de pesquisa bibliográfica para desenvolvimento de cada tema a ser problematizado. Ao final, é possível concluir pela caracterização do Direito Penal do inimigo como um Direito de exceção, incompatível com o modelo de Estado de Direito.

Palavras-chave: Estado de Direito. Estado de Exceção. Direito Penal do inimigo.

* Doutor em Direito pela Universidad Autónoma de Madrid. Doutor honoris causa pela Universidade Autónoma de Tlaxcala - México. Doutor honoris causa pelo Centro Universitário del Valle de Teotihuacan - México. Realizou estudos de pós-doutorado na Universidad Autónoma de Madrid sob a direção do Prof. Dr. Manuel Cancio Meliá. Professor de Direito Penal nos Cursos de graduação e pós-graduação da Escola de Direito da Universidade do Vale do Rio dos Sinos - UNISINOS. Advogado Criminalista. Currículo Lattes: http://lattes. cnpq.br/8717437776868647. E-mail: <callegari@callegariadvogados.com.br>.

** Mestrando em Direito Público no Programa de Pós-Graduação em Direito da UNISINOS. Bolsista CAPES-PROEX. Membro do grupo de pesquisa "Sistemas Punitivos", sob a coordenação do prof. Dr. André Luís Callegari. Integrante do projeto de pesquisa "Estado e Política Criminal: a expansão do Direito Penal como forma de combate ao terrorista". Advogado criminalista. Currículo Lattes: http://lattes.cnpq.br/8294267921609931. E-mail: <raul@ ritterlinhares.com.br>. 


\section{INTRODUÇÃO}

O presente artigo apresenta, em seu conteúdo, os resultados parciais do desenvolvimento de parte da primeira fase do projeto de pesquisa intitulado "Um discurso sobre o Direito Penal de exceção: a luta contra o terrorista”, financiado pelo Conselho Nacional de Desenvolvimento Científico e Tecnológico (CNPq), órgão brasileiro voltado ao fomento à pesquisa.

Nessa primeira fase do projeto de pesquisa, verificou-se que alguns fenômenos presentes nos estudos político-criminais modernos têm sido apontados como reflexos de uma nova postura social e jurídica em relação à delinquência. Essa postura foi denominada por Jesús-María Silva Sánchez de "expansão do Direito Penal"2.

Uma das concepções mais representativas dessa expansão é a teoria do Direito Penal do inimigo, defendida, sobretudo, por Günther Jakobs, que institui uma separação entre classes distintas de pessoas, divididas em cidadãos e inimigos e sujeitas a um tratamento jurídico completamente distinto.

Nesse modelo, o sujeito considerado inimigo é despojado de seus direitos e tratado como mero objeto de inocuização em prol da defesa da sociedade. Essa lógica, contudo, apresenta íntima relação com aquela presente em estados de exceção, nos quais o poder punitivo estatal não encontra limitação em critérios seguros.

Portanto, com o presente trabalho, pretende-se estabelecer a (in)compatibilidade da racionalidade do Direito Penal do inimigo com o modelo de Estado de Direito atual.

Para tanto, realizar-se-á a construção do sentido do Estado de Direito, com uma passagem pelo surgimento histórico dessa concepção, destacando-se o que se refere especificamente ao Direito Penal, especialmente a concepção material de limitação do poder punitivo do Estado.

Por fim, será abordado o Estado de Exceção e uma possível relação com o Direito Penal do inimigo, para que se possa contrapor esse modelo penal com os postulados do Estado de Direito.

\section{O ESTADO DE DIREITO}

O signo "Estado de Direito" possui amplas variações de significado no decorrer da história do pensamento político. ${ }^{3}$ Essa variação de significado é verificada não só temporal, mas também em um plano geográfico, motivo pelo qual J. J. Gomes Canotilho destaca o cuidado necessário ao se igualar os signos Rechtsstaat (alemão), Rule of Law (britânico) e État Légal (francês). ${ }^{4}$

Foi com o Rechtsstaat alemão que surgiu, pela primeira vez, no século XIX, a ideia de Estado de Direito. Esse termo foi utilizado pelo autor alemão Carl Th. Welcker, no ano de 1813, período no qual o Estado de Direito significava 
o Estado do Direito racional, ou seja, o Estado que realiza princípios racionais em prol da vida em comum dos homens ${ }^{5}$ ou, ainda, a limitação do Estado em benefício da autodeterminação das pessoas. ${ }^{6}$

Esse conceito de Estado de Direito incluía algumas características, dentre as quais a renúncia de todo o caráter transpessoal do Estado, com a priorização do interesse comum das pessoas, ponto de partida e referência do ordenamento jurídico; a atividade estatal voltada à proteção das liberdades individuais e à garantia da possibilidade de desenvolvimento pessoal dos cidadãos; e os princípios racionais utilizados como fundamentos da organização do Estado e regulação da sua atividade, o que implica o reconhecimento dos direitos básicos dos cidadãos (liberdade civil, igualdade jurídica, garantia da propriedade etc.), da independência dos juízes, de um governo constitucionalmente responsável, do domínio da lei e da participação popular no Legislativo. ${ }^{?}$

Ainda, destaca-se a importância da lei ${ }^{8}$ nessa significação de Estado de Direito, a qual é considerada como elemento de vinculação e limitação da atividade estatal. ${ }^{9}$

À medida que se volta a tornar possível a autorrealização individual das pessoas, esse conceito confere importância significativa à garantia da liberdade e da propriedade, configurando-se esse Estado de Direito como marcadamente burguês. ${ }^{10}$ Nesse sentido, a Administração apenas poderia intervir em ambos os direitos fundamentais (liberdade e propriedade) quando tal intervenção fosse permitida por lei, aprovada pela representação popular. ${ }^{11}$

Nesse contexto, tem-se que, em um primeiro momento, a expressão "Estado de Direito" tende a ser identificada com o próprio Estado Liberal, caracterizado pela limitação do poder dos governantes por um conjunto de técnicas e princípios. ${ }^{12} \mathrm{O}$ Estado de Direito nesse momento histórico, concebido pelo pensamento liberal, estruturou-se como um modelo de proteção de direitos de liberdade por meio da criação de obrigações negativas ao Estado. Desse modo, limita-se o exercício do poder, que esbarra em direitos invioláveis. ${ }^{13}$

Esse modelo de Estado, ao final, realizou uma importante tarefa limitadora do poder soberano do Estado, conforme destaca J. J. Gomes Canotilho: "As ideias do 'governo de leis e não de homens', de 'Estado submetido ao direito', de 'constituição como vinculação jurídica do poder', foram, como vimos, tendencialmente realizadas por institutos como os de rule of law, due process of law, Rechtsstaat, principe de la légalité". ${ }^{14}$ Trata-se da primazia da lei sobre a vontade caprichosa de um soberano. ${ }^{15}$

Com o colapso do Estado liberal burguês até então dominante, surge o fenômeno conhecido como Estado social, no qual Estado e sociedade não mais são concebidos como sistemas autônomos, passando a se relacionarem intimamente ${ }^{16}$ Esse processo de alteração de perspectiva se deve ao surgimento de novas demandas sociais, ${ }^{17}$ bem como ao fato de o modelo originário de Estado de Direito, de caráter liberal (burguês), ter sido considerado incapaz de 
oferecer respostas à desigualdade social a qual ele mesmo fomenta. Por isso, desenvolveu-se a concepção de Estado Social de Direito, que não deixa de lado a tutela das liberdades individuais, mas que insere em suas preocupações o desenvolvimento social. ${ }^{18} \mathrm{Ou}$ seja, o Estado de Direito social é pensado como complemento do Estado de Direito liberal, somando às proibições ao atuar do Estado uma série de obrigações positivas correspondentes aos direitos sociais, que devem ser efetivados pelo Estado. ${ }^{19}$

Verifica-se a inserção de um conteúdo material ao Estado de Direito, perspectiva na qual a Constituição deixa de apenas fixar os limites da atuação do Estado, convertendo-se na positivação de valores fundamentais da vida em sociedade. ${ }^{20}$

Assim, a limitação do poder do Estado por meio do Direito não é estabelecida apenas como mero critério formal ou procedimental, passando a englobar, também, um determinado conteúdo. O Estado de Direito é, além de forma, matéria. Nessa perspectiva,

[...] como meio de ordenação racional, o direito é indissociável da realização da justiça, da efectivação de valores políticos, económicos, sociais e culturais; como forma, ele aponta para a necessidade de garantias jurídico-formais de modo a evitar acções e comportamentos arbitrários e irregulares de poderes públicos. ${ }^{21}$

O Estado "material" de Direito estabelece valores e princípios jurídicos superiores que vinculam o poder estatal, especialmente com a obrigação ao poder público de garantia e realização dos direitos fundamentais. ${ }^{22}$

Nesse caminho, abandonado o caráter meramente formal do Estado de Direito, Lenio Luiz Streck defende que, sob a ótica do Estado Democrático de Direito, "[...] o Direito deve ser visto como instrumento de transformação social $[\ldots] " .23$

Dessa forma, quando se refere a Estado de Direito, está-se a defender que "[...] as instituições políticas e os aparelhos jurídicos tenham rigorosamente por finalidade a garantia dos direitos subjetivos". ${ }^{24}$

Luigi Ferrajoli, fazendo referência a uma concepção de Estado de Direito proposta por Norberto Bobbio, destaca esse modelo como um governo submetido a leis (sub lege) ou um governo exercido por meio de leis gerais e abstratas (per leges). ${ }^{25}$

O governo per leges é caracterizado pela existência de normas gerais, abstratas e fruto de uma vontade coletiva, a reduzir o risco de exercício desenfreado do poder, servindo de garantia à igualdade (por sua abstração e generalidade) e à liberdade (enquanto fruto da vontade geral). Por sua vez, o governo sub lege significa que qualquer poder deva ser conferido (exercido conforme as formalidades legais) ou limitado (não só em relação à forma ou ao procedimento, mas, também, quanto ao conteúdo daquilo que pode dispor) por lei. ${ }^{26}$

No campo penal, Luigi Ferrajoli conclui que o Estado de Direito possui ambas as acepções: 
[...] o poder judicial de apurar e punir os crimes é, por certo, sub lege tanto quanto o poder legislativo de defini-los é exercido per leges; e o poder legislativo é exercido per leges enquanto, por seu turno, está sub leges, isto é, está prescrita pela lei constitucional a reserva de lei geral e abstrata em matéria penal. ${ }^{27}$

O autor não se limita, porém, a uma concepção meramente formal da limitação legal da atuação do Estado, próprio de um "Estado legal". Além da vinculação legal/formal da atuação estatal (resultado do princípio da legalidade, apontado por Santiago Mir Puig como imposição do Estado de Direito, ${ }^{28}$ sendo a fonte da legitimação formal do poder), concebe-se uma substancial vinculação dos poderes do Estado com a finalidade de garantia dos direitos fundamentais (fonte de legitimação substancial do poder)..$^{29}$

Nesse mesmo sentido, destaca Norberto Bobbio, no tocante à limitação do poder estatal:

Costuma-se chamar de "constitucionalismo" à teoria e à prática dos limites do poder: pois bem, o constitucionalismo encontra a sua plena expressão nas constituições que estabelecem limites não só formais mas também materiais ao poder político, bem representados pela barreira que os direitos fundamentais, uma vez reconhecidos e juridicamente protegidos, erguem contra a pretensão e a presunção do detentor do poder soberano de submeter à regulamentação todas as ações dos indivíduos e dos grupos. ${ }^{30}$

Alguns dos princípios inerentes a esse Estado de Direito são elencados por J. J. Gomes Canotilho, quais sejam os princípios da legalidade da administração, da segurança jurídica e da proteção da confiança dos cidadãos, da proibição do excesso, da proteção jurídica e das garantias processuais. ${ }^{31}$

Também nesse sentido, Ernesto Benda estabelece, como elementos essenciais do Estado de Direito, a segurança jurídica, a constituição como norma suprema, ${ }^{32}$ a vinculação jurídica dos poderes públicos à lei e ao Direito, a divisão dos poderes, a proteção dos direitos fundamentais e a proteção da confiança jurídica. ${ }^{33}$

Já especificamente no âmbito do Direito Penal, Enrique Bacigalupo aponta como princípios penais referentes ao Estado de Direito aqueles relacionados à previsibilidade da ação repressiva pelo cidadão e à limitação dessa atuação repressiva estatal, elementos representados pelo princípio da legalidade, pelo princípio da culpabilidade, pelo princípio da proporcionalidade e pela proibição de bis in idem. ${ }^{34}$

Percebe-se, nesse caso, a configuração de critérios materiais a fundamentar os limites e a atuação do Direito Penal em um Estado de Direito. A concepção material do Estado de Direito, aliás, é referida por Hans-Heinrich Jescheck e Thomas Weigend como sendo o indicativo de como o Direito Penal deve ser configurado para que corresponda à figura ideal de Estado justo. Para tanto, os 
autores recorrem a balizas como o respeito à dignidade da pessoa, a vinculação da atuação penal à necessidade político-criminal, a proibição de excesso ou o princípio da proporcionalidade, bem como o princípio da igualdade. ${ }^{35}$

Dessa forma, em um Estado de Direito, outro Direito Penal não pode haver que não um de caráter garantista. As garantias penais e processuais penais são o próprio Estado de Direito, na contenção do poder desmedido e do Estado de polícia. ${ }^{36}$

\section{ODIREITOPENALDOINIMIGO:QUEBRADOESTADODEDIREITO E NORMALIZAÇÃO DO ESTADO DE EXCEÇÃO}

No campo político-criminal, verificou-se, nas últimas décadas, uma transição de debates abolicionistas e reducionistas a discursos expansivos do poder punitivo estatal. ${ }^{37}$

Diversos são os fatores que propulsionam esse movimento expansivo do Direito Penal na atual sociedade. Dentre eles, Jesús-María Silva-Sánchez aponta o surgimento de novos riscos e interesses passíveis de tutela (novos bens jurídicos), a sensação generalizada de insegurança presente nesse modelo de configuração social (muito relacionado com a atuação dos meios de comunicação), a identificação da maioria da sociedade com a vítima do delito e a falta de preocupação com o delinquente, ${ }^{38}$ entre outros motivos. ${ }^{39}$

Abordando especificamente a atuação da mídia, José Luis Díez Ripollés concebe o atual contexto social como um excelente mercado para notícias que causam impacto social, revolta e insegurança. ${ }^{40}$ Nesse sentido, a atual sociedade é, por vezes, qualificada como a "sociedade da insegurança sentida", o que se origina especialmente em razão da revolução dos meios de comunicação e da dificuldade em se obter informações confiáveis. ${ }^{41}$

Com isso, desenvolve-se um anseio social pelo fortalecimento do sentimento de segurança. Como contrapartida, alguns programas de intervenção penal não objetivam propriamente o tratamento do problema da violência, mas se destinam a controlar os sentimentos sociais, passando a imagem à população de que medidas estão sendo tomadas em seu benefício. ${ }^{42}$

O recurso ao Direito Penal surge, então, como medida instantânea de controle das insatisfações da sociedade no tocante à insegurança, desenvolvendo o que se designou como "Direito Penal simbólico", 43 apontado por Winfried Hassemer como um dos fenômenos da crise do Direito Penal. ${ }^{44}$ Assim, ao procurar se eximir de tarefas próprias de um agente social de bem-estar, o Estado se utiliza apenas de seu aparato repressivo na condução do tratamento do delito. ${ }^{45}$

Com essa tendência à expansão do âmbito de atuação do Direito Penal, verifica-se, por exemplo, um processo de flexibilização dos critérios de imputação e das garantias penais e processuais penais, ${ }^{46}$ características inerentes ao Estado de Direito. ${ }^{47}$ Eugênio Raul Zaffaroni aponta como alguns dos efeitos da raciona- 
lidade expansiva do Direito Penal a antecipação das barreiras punitivas aos atos preparatórios, a desproporção das consequências jurídicas, a flexibilização das garantias processuais, a instituição do Direito Penal do autor, a disseminação de tipos penais de perigo abstrato, entre outras características. ${ }^{48}$

O destaque do caráter expansionista do Direito Penal moderno e a maior parte das características mencionadas acima são encontradas na teoria denominada "Direito Penal do inimigo", defendida e desenvolvida por Günther Jakobs, teoria na qual esse autor realiza a distinção entre pessoas com os status de "cidadão" e de "inimigo", cada qual titular de uma forma peculiar de aplicação do Direito Penal. Para o primeiro (cidadão), todas as garantias do Direito são asseguradas e é preservado o seu status de titular de direitos, pois permanece ele sendo considerado um membro da sociedade. Ao inimigo, contudo, são subtraídos direitos e garantias, aplicando-se um Direito Penal distinto, marcado por uma atuação rigorosa, destinada à inocuização do indivíduo, considerado já um inimigo do Estado. ${ }^{49}$

Esse modelo de Direito Penal, voltado ao inimigo, possui características presentes em um verdadeiro Estado de Exceção, incompatível com o modelo de Estado de Direito. O Direito Penal do inimigo, acima de tudo, caracteriza-se pela transposição, pelo Estado, dos limites impostos a si no exercício do poder punitivo, configurando-se uma prática marcadamente excepcional da punição.

O Estado de Exceção, nesse aspecto, é considerado como a capacidade que se reserva o Estado de ampliação da violência estatal com a suspensão ou, até mesmo, violação da lei, o que pode ocorrer, por exemplo, em "estados de sítio" ou "estados de emergência". Apesar dessa identificação do Estado de Exceção com as situações pontuais e transitórias mencionadas, nem sempre ele se verifica em momentos excepcionais de perigo à ordem estabelecida. Atualmente, pode-se constatar a presença do Estado de Exceção como "norma" de tratamento de partes específicas da sociedade, como, nos exemplos oferecidos por Pilar Calveiro, os grupos indígenas, os acusados de terrorismo ou de tráfico de drogas etc. ${ }^{50}$ destacando-se o terrorismo como principal fenômeno propulsor da teoria do Direito Penal do inimigo, verdadeiro Direito Penal excepcional tendente a tornar-se permanente.

Citando um exemplo de Estado de Exceção permanente, Giorgio Agamben aponta o período do Terceiro Reich alemão, no qual Adolf Hitler promulgou, assim que tomou o poder do Estado alemão, o "Decreto para a proteção do povo e do Estado", suspendendo dispositivos da Constituição de Weimar referentes a liberdades individuais. A medida, a princípio transitória, não foi revogada, e esse Estado de Exceção perdurou por doze anos. ${ }^{51}$

Casos como esse constituem Estados de exceção que se ordinarizam e se convertem em "exceção perpétua", ${ }^{52}$ caracterizando-se pela prática da atribuição a parte da sociedade do status de excluídos, aqueles que não possuem bens e tutela do Direito ou que, os possuindo, podem ser despojados deles (inclusive da própria vida), classificados por Pilar Calveiro de "prescindíveis-perigosos". ${ }^{53}$ 
Portanto, junto dos limites da atuação do poder estatal (característicos do Estado de Direito), encontram-se espaços de exceção nos quais a proteção legal resta suspensa para dar lugar a diferentes intensidades e formas de violência estatal, legitimadas pela criação de figuras como a de "combatentes inimigos", os quais devem ser enfrentados em nome da segurança nacional. ${ }^{54}$

Como exemplo desse espaço de exceção Giorgio Agamben menciona o USA Patriot Act, promulgado pelo Senado estadunidense, cuja inovação “[...] está em anular radicalmente todo estatuto jurídico do indivíduo, produzindo, dessa forma, um ser juridicamente inominável e inclassificável". ${ }^{5}$

Nesse sistema de exceção, destacam-se as legislações marcadas pelos ideários de segurança nacional ou segurança cidadã, qualificações que Francisco Muñoz Conde entende serem próprias de Estados autoritários, utilizadas como pretexto para a restrição de direitos fundamentais, declarada essa restrição como necessária para uma maior proteção da paz social. ${ }^{56}$

Dessa forma, a prática da exceção conduz a uma involução no ordenamento punitivo, promovendo a adoção de práticas e institutos penais ultrapassados e incompatíveis com o sistema penal vigente em um Estado de Direito. ${ }^{57}$

No caso do Direito Penal do inimigo, concebe-se um verdadeiro Direito Penal de exceção, caracterizado por Luigi Ferrajoli em dois aspectos: "[...] a legislação de exceção em relação à Constituição e, portanto, a mutação legal das regras do jogo; a jurisdição de exceção, por sua vez degradada em relação à mesma legalidade alterada." ${ }^{58}$

Pode-se perceber que o Estado de Direito dificilmente admite distinções como a proposta por Günther Jakobs, que criam sujeitos com distintos níveis de respeito e proteção jurídicos, pois as garantias fundamentais próprias do Direito Penal e Direito Processual Penal são irrenunciáveis nesse modelo de Estado de Direito. ${ }^{59}$

Nesse sentido, Francisco Muñoz Conde identifica o Direito Penal do inimigo como um tipo de Direito Penal excepcional violador de princípios próprios do Estado de Direito, como o da legalidade, da proporcionalidade, da culpabilidade e, principalmente, de princípios processuais como o da presunção de inocência e do devido processo legal. ${ }^{60}$

Nesse Direito Penal do inimigo, a lógica do Estado de Direito é sacrificada em prol de medidas destinadas à proteção do Estado a todo custo, não mais havendo a limitação da atuação estatal pelas regras jurídicas ordinárias, ou seja, nos moldes do Direito Penal do inimigo, tem-se um puro Direito de Estado, no qual os interesses do Estado sujeitam do próprio Direito. ${ }^{61}$ Nesse sentido, o Direito é o que convém ao Estado em dado momento, sendo o pior possível para seus inimigos. ${ }^{62}$

Essa "razão de Estado" concebe o próprio Estado como fim, subordinando os meios a serem utilizados (indeterminados e não reguláveis) aos fins políticos. 
Nesse caso, os meios jurídicos disponíveis à perseguição dos fins políticos são flexíveis, manipuláveis pelo arbítrio do titular do poder estatal. Ao contrário, o "Estado de direito" surge como teoria voltada à priorização da subordinação dos fins políticos ao respeito aos meios jurídicos disponíveis para tanto, vinculados à limitação legal. Não mais como próprio fim fundado em si mesmo, o Estado passa a ser meio fundado na tutela de direitos fundamentais das pessoas e sujeito a regras constitucionais rígidas. ${ }^{63}$

Nesse embate entre "razão de Estado" e "Estado de Direito", a primeira se apresenta com uma força de legitimação política até mesmo maior do que nos Estados absolutos ou totalitários, conforme entendimento de Luigi Ferrajoli,

[...] seja porque o Estado que a tutela é o Estado valorado como "democrático" ou "constitucional" ou "de direito", seja porque a mutação dos meios legais é apresentada não já como praxe ordinária de governo, mas como medida excepcional para afrontar o risco da sua eversão. Mas é claro que a contradição se dá em termos: a ruptura das regras do jogo se dá, de fato, neste caso, invocando a tutela das mesmas regras do jogo; $\mathrm{O}$ Estado de direito é defendido mediante sua negação. ${ }^{64}$

Há, então, uma mutação da fonte de legitimação externa do Direito Penal, passando essa função (de legitimar o Direito Penal) a ser exercida não mais pelas regras do Estado de Direito, com seus vínculos garantistas, mas pela razão de Estado e sua supremacia ao objetivo de luta contra a criminalidade. ${ }^{65}$

Nesse caminhar, a ânsia de combate ao crime em um Estado de Direito torna possível a implementação de medidas excepcionais, contrárias ao próprio Estado de Direito ao qual visa proteger, instituindo-se um verdadeiro Estado de exceção permanente em relação a determinados tipos de delitos ou a determinadas classes de pessoas, como ocorre, por exemplo, com o delito de terrorismo (ou com o estereótipo "sujeito terrorista").

Dessa forma, O Direito Penal do inimigo representa um típico Direito de exceção, violador de princípios inerentes ao Estado de Direito e, por isso, inaplicável nesse modelo de Estado, mesmo que sob o pretexto de sua conservação.

\section{CONCLUSÃO}

Analisando a aplicação do Direito Penal do inimigo aos atos de terrorismo, Francisco Muñoz Conde se questiona, como forma de crítica à normalização da exceção e o risco de que isso alimente novas práticas excepcionais no Direito Penal:

¿Qué pasaría si después de convertirse este Derecho penal del enemigo en realidad habitual y corriente en nuestras democracias, siguen cometiéndose o incluso se incrementan las acciones terroristas y las respuestas también terroristas del Estado a las mismas? ¿Se reintroducirá la tortura como medio de investigación?; ise abrirán campos de concentración para los enemigos? ise admitirá la 
detención policial, sin intervención judicial? ise generalizará la aplicación de la pena de muerte y se encargarán de ello Tribunales militares de excepción? ${ }^{36}$

O questionamento de Francisco Muñoz Conde reflete um caminho possível decorrente da introdução do Direito penal excepcional do inimigo no Estado de Direito, com a regularização da exceção e a introdução posterior de medidas ainda mais rigorosas.

Concebendo-se os princípios básicos inerentes ao Estado de Direito e a sua irrenunciabilidade, tem-se que, em matéria penal, esse modelo de Estado não concebe a possibilidade de instituição da distinção de tratamento "amigo/ inimigo" proposta por Günther Jakobs, distinção marcada por uma razão de Estado, apenas se admitindo o tratamento "inocente/culpado". Exceções às regras no Estado de Direito devem ser concebidas sempre como antijurídicas. ${ }^{67}$

Portanto, delimitadas as balizas do Estado de Direito, com as limitações ao exercício do poder punitivo estatal e a obrigatoriedade de preservação dos direitos fundamentais, o Estado de Exceção, representado pelo Direito Penal do inimigo, deve ser tomado como incompatível em quaisquer circunstâncias com o modelo de Estado de Direito.

\section{REFERÊNCIAS}

AGAMBEN, Giorgio. Estado de exceção. Tradução de Iraci D. Poleti. 2. ed. São Paulo: Boitempo, 2004.

ÁLVAREZ CONDE, Enrique. Curso de Derecho Constitucional: el estado constitucional, el sistema de fuentes, los derechos y libertades. 3. ed. Madrid: Editorial Tecnos, 1999. v. 1.

BACIGALUPO, Enrique. Derecho penal y el Estado de Derecho. Chile: Editorial Jurídica de Chile, 2005.

BENDA, Ernesto. El Estado social de Derecho. In: BENDA, Ernesto et al. (Org.). Manual de Derecho Constitucional. Tradução de Antonio López Pina. Madrid: Marcial Pons, 1996. p. 487-559.

BIANCHI, Alberto B. Dinámica del Estado de Derecho: la seguridad jurídica ante las emergencias. Buenos Aires: Editorial Ábaco de Rodolfo Depalma, 1996.

BOBBIO, Norberto. Estado, governo, sociedade: para uma teoria geral da política. Tradução de Marco Aurélio Nogueira. Rio de Janeiro: Paz e Terra, 1987.

BÖCKENFÖRDE, Ernst Wolfgang. Estudios sobre el Estado de Derecho y la democracia. Tradução de Rafael de Agapito Serrano. Madrid: Editorial Trotta S.A., 2000.

CADEMARTORI, Sergio. Estado de Direito e Legitimidade: uma abordagem garantista. 2. ed. Campinas, SP: Millennium Editora, 2006. 
CALLEGARI, André Luís; WERMUTH, Maiquel Ângelo Dezordi. Sistema Penal e Política Criminal. Porto Alegre: Livraria do Advogado, 2010.

CALVEIRO, Pilar. Estado, Estado de excepción y violencia. Revista de Ciencias Sociales. Montevidéu, n. 24, ano XXI, p. 95-100, 2008.

CANOTILHO, J. J. Gomes. Direito Constitucional e teoria da Constituição. 7. ed. Coimbra: Edições Almedina, 2003.

CORCOY BIDASOLO, Mirentxu. Expansión del derecho penal y garantías constitucionales. Revista de Derechos Fundamentales, Chile, n. 8, p. 45-76, 2012.

COSTA, Pietro. O Estado de Direito: uma introdução história. In: COSTA, Pietro; ZOLO, Danilo (Org.). O Estado de Direito. História, teoria, crítica. Tradução de Carlo Alberto Dastoli. São Paulo: Martins Fontes, 2006. p. 95-198. DÍEZ RIPOLLÉS, José Luis. La política criminal en la encrucijada. Buenos Aires: B de F, 2007.

FERRAJOLI, Luigi. Direito e razão: teoria do garantismo penal. Tradução de Ana Paula Zomer Sica, Fauzi Hassan Choukr, Juarez Tavares e Luiz Flávio Gomes. 3. ed. São Paulo: Revista dos Tribunais, 2010.

HASSEMER, Winfried. Direito penal: fundamentos, estrutura, política. Organização e revisão de Carlos Eduardo de Oliveira. Tradução de Adriana Beckman Meirelles et al. Porto Alegre: Sergio Antonio Fabris, 2008.

JAKOBS, Günther; CANCIO MELIÁ, Manuel. Direito penal do inimigo: noções e críticas. Organização e tradução de André Luís Callegari e Nereu José Giacomolli. 6. ed. Porto Alegre: Livraria do Advogado, 2012.

JESCHECK, Hans-Heincrich; WEIGEND, Thomas. Tratado de derecho penal: parte general. Tradução de Miguel Olmedo Cardenete. 5. ed. Granada: Editorial Comares, 2002.

LEAL, Mônia Clarissa Hennig. Estado de Direito. In: BARRETO, Vicente de Paulo (Coord.). Dicionário de filosofia do Direito. São Leopoldo: UNISINOS, 2006. p. 288-291.

MIR PUIG, Santiago. Derecho penal: parte general. 7. ed. Barcelona: Editorial Reppertor, 2005.

MUÑOZ CONDE, Francisco. La generalización del derecho penal de excepción: tendencias legislativas y doctrinales: entre la tolerancia cero y el derecho penal del enemigo. Revista Ciencia Jurídica, Chile, n. 1, ano 1, p. 113-142, 2011.

PÉREZ CEPEDA, Ana Isabel. La seguridad como fundamento de la deriva del Derecho penal postmoderno. Madrid: Editora Iustel, 2007.

RUFFÌA, Paolo Biscaretti di. Introducción al derecho constitucional comparado. Las "formas de Estado" y las "formas de gobierno". Las Constituiciones modernas. Tradução de Héctor Fix-Zamudio. México: Fondo de Cultura Económica, 1996. 
SÁNCHEZ, Jesús-María Silva. La expansión del derecho penal: aspectos de la política criminal en las sociedades postindustriales. 2. ed. Madrid: Civitas, 2001.

STRECK, Lenio Luiz. Hermenêutica jurídica e (m) crise: uma exploração hermenêutica da construção do Direito. 10. ed. Porto Alegre: Livraria do Advogado, 2011.

ZAFFARONI, Eugenio Raúl. O inimigo no direito penal. 3. ed. Trad. De Sérgio Lamarão. Rio de Janeiro: Revan, 2011.

ZOLO, Danilo. Teoria e crítica do Estado de Direito. In: COSTA, Pietro; ZOLO, Danilo (Org.). O Estado de Direito. História, teoria, crítica. Tradução de Carlo Alberto Dastoli. São Paulo: Martins Fontes, 2006. p. 3-94.

1 O presente artigo apresenta em seu conteúdo os resultados parciais do desenvolvimento do projeto de pesquisa intitulado "Um discurso sobre o Direito Penal de exceção: a luta contra o terrorista", com fomento do Conselho Nacional de Desenvolvimento Científico e Tecnológico - CNPq, aprovado na Chamada Universal 14/2012.

2 SÁNCHEZ, Jesús-María Silva. La expansión del derecho penal: aspectos de la política criminal en las sociedades postindustriales. 2. ed. Madrid: Civitas, 2001.

3 FERRAJOLI, Luigi. Direito e razão: teoria do garantismo penal. Tradução de Ana Paula Zomer Sica, Fauzi Hassan Choukr, Juarez Tavares e Luiz Flávio Gomes. 3. ed. São Paulo: Revista dos Tribunais, 2010, p. 789. No mesmo sentido: ZOLO, Danilo. Teoria e crítica do Estado de Direito. In: COSTA, Pietro; ZOLO, Danilo (Org.). O Estado de Direito. História, teoria, crítica. Tradução de Carlo Alberto Dastoli. São Paulo: Martins Fontes, 2006. p. 8.

4 CANOTILHO, J. J. Gomes. Direito Constitucional e teoria da Constituição. 7. ed. Coimbra: Edições Almedina, 2003. p. 93.

5 BÖCKENFÖRDE, Ernst Wolfgang. Estudios sobre el Estado de Derecho y la democracia. Tradução de Rafael de Agapito Serrano. Madrid: Editorial Trotta S.A., 2000. p. 19.

6 CANOTILHO, J. J. Gomes. Direito Constitucional e teoria da Constituição. 7. ed. Coimbra: Edições Almedina, 2003. p. 96-97.

7 BÖCKENFÖRDE, Ernst Wolfgang. Estudios sobre el Estado de Derecho y la democracia. Tradução de Rafael de Agapito Serrano. Madrid: Editorial Trotta S.A., 2000. p. 19-20.

8 É essa uma possível resposta ao questionamento histórico retomado por Norberto Bobbio a respeito da relação entre poder e direito: "É melhor o governo das leis ou o governo dos homens?" (BOBBIO, Norberto. Estado, governo, sociedade: para uma teoria geral da política.Tradução de Marco Aurélio Nogueira. Rio de Janeiro: Paz e Terra, 1987. p. 95-96).

9 BÖCKENFÖRDE, Ernst Wolfgang. Estudios sobre el Estado de Derecho y la democracia. Tradução de Rafael de Agapito Serrano. Madrid: Editorial Trotta S.A., 2000. p. 23.

10 Ibid., p. 22.

11 CANOTILHO, J. J. Gomes. Direito Constitucional e teoria da Constituição. 7. ed. Coimbra: Edições Almedina, 2003. p. 97.

12 ÁLVAREZ CONDE, Enrique. Curso de Derecho Constitucional: el estado constitucional, el sistema de fuentes, los derechos y libertades. 3. ed. Madrid: Editorial Tecnos, 1999. v. 1. p. 93.

13 CADEMARTORI, Sergio. Estado de Direito e Legitimidade: uma abordagem garantista. 2. ed. Campinas: Millennium Editora, 2006. p. 209-210.

14 CANOTILHO, J. J. Gomes. Direito Constitucional e teoria da Constituição. 7. ed. Coimbra: Edições Almedina, 2003. p. 98.

15 BIANCHI, Alberto B. Dinámica del Estado de Derecho: la seguridad jurídica ante las emergencias. Buenos Aires: Editorial Ábaco de Rodolfo Depalma, 1996. p. 81.

16 ÁLVAREZ CONDE, Enrique. Curso de Derecho Constitucional: el estado constitucional, el sistema de fuentes, los derechos y libertades. 3. ed. Madrid: Editorial Tecnos, 1999. v. 1. p. 109-110.

17 LEAL, Mônia Clarissa Hennig. Estado de Direito. In: BARRETO, Vicente de Paulo (Coord.). Dicionário de filosofia do Direito. São Leopoldo: Editora UNISINOS, 2006. p. 291. 
18 BÖCKENFÖRDE, Ernst Wolfgang. Estudios sobre el Estado de Derecho y la democracia. Tradução de Rafael de Agapito Serrano. Madrid: Editorial Trotta S.A., 2000. p. 35-40.

19 CADEMARTORI, Sergio. Estado de Direito e Legitimidade: uma abordagem garantista. 2. ed. Campinas: Millennium Editora, 2006. p. 210.

20 BÖCKENFÖRDE, Ernst Wolfgang. Estudios sobre el Estado de Derecho y la democracia. Tradução de Rafael de Agapito Serrano. Madrid: Editorial Trotta S.A., 2000. p. 40.

21 CANOTILHO, J. J. Gomes. Direito Constitucional e teoria da Constituição. 7. ed. Coimbra: Edições Almedina, 2003. p. 244.

22 BENDA, Ernesto. El Estado social de Derecho. In: BENDA, Ernesto et al. (Org.). Manual de Derecho Constitucional. Tradução de Antonio López Pina. Madrid: Marcial Pons, 1996. p. 490-491.

23 STRECK, Lenio Luiz. Hermenêutica jurídica e (m) crise: uma exploração hermenêutica da construção do Direito. 10. ed. Porto Alegre: Livraria do Advogado, 2011. p. 43.

24 ZOLO, Danilo. Teoria e crítica do Estado de Direito. In: COSTA, Pietro; ZOLO, Danilo (Org.). O Estado de Direito. História, teoria, crítica. Tradução de Carlo Alberto Dastoli. São Paulo: Martins Fontes, 2006. p. 5.

25 FERRAJOLI, Luigi. Direito e razão: teoria do garantismo penal. Tradução de Ana Paula Zomer Sica, Fauzi Hassan Choukr, Juarez Tavares e Luiz Flávio Gomes. 3. ed. São Paulo: Revista dos Tribunais, 2010. p. 789.

26 CADEMARTORI, Sergio. Estado de Direito e Legitimidade: uma abordagem garantista. 2. ed. Campinas: Millennium Editora, 2006. p. 11-13.

27 FERRAJOLI, Luigi. Direito e razão: teoria do garantismo penal. Tradução de Ana Paula Zomer Sica, Fauzi Hassan Choukr, Juarez Tavares e Luiz Flávio Gomes. 3. ed. São Paulo: Revista dos Tribunais, 2010. p. 789.

28 MIR PUIG, Santiago. Derecho penal: parte general. 7. ed. Barcelona: Editorial Reppertor, 2005. p. 113.

29 FERRAJOLI, Luigi. Direito e razão: teoria do garantismo penal. Tradução de Ana Paula Zomer Sica, Fauzi Hassan Choukr, Juarez Tavares e Luiz Flávio Gomes. 3. ed. São Paulo: Revista dos Tribunais, 2010. p. 790.

30 BOBBIO, Norberto. Estado, governo, sociedade: para uma teoria geral da política. Tradução de Marco Aurélio Nogueira. Rio de Janeiro: Paz e Terra, 1987. p. 101.

31 CANOTILHO, J. J. Gomes. Direito Constitucional e teoria da Constituição. 7. ed. Coimbra: Edições Almedina, 2003. p. 256-278.

32 Na mesma linha defendida por Paolo Biscaretti di Ruffia, para quem o Estado de Direito é caracterizado pela limitação eficaz da atividade governamental por meio de constituições escritas, normalmente classificadas como rígidas, em razão da criação de procedimentos mais complexos para sua alteração. (RUFFÌA, Paolo Biscaretti di. Introducción al derecho constitucional comparado. Las "formas de Estado" y las "formas de gobierno". Las Constituiciones modernas. Tradução de Héctor Fix-Zamudio. México: Fondo de Cultura Económica, 1996. p. 114-115).

33 BENDA, Ernesto. El Estado social de Derecho. In: BENDA, Ernesto et al. (Org.). Manual de Derecho Constitucional. Tradução de Antonio López Pina. Madrid: Marcial Pons, 1996. p. 493-509.

34 BACIGALUPO, Enrique. Derecho penal y el Estado de Derecho. Chile: Editorial Jurídica de Chile, 2005. p. 104.

35 JESCHECK, Hans-Heincrich; WEIGEND, Thomas. Tratado de derecho penal: parte general. Tradução de Miguel Olmedo Cardenete. 5. ed. Granada: Editorial Comares, 2002. p. 28-29.

36 ZAFFARONI, Eugenio Raúl. O inimigo no direito penal. 3. ed. Trad. De Sérgio Lamarão. Rio de Janeiro: Revan, 2011. p. 173.

37 Ibid., p. 13.

38 O que levou Mirentxu Corcoy Bidasolo a referir a deformação do princípio in dubio pro reo, que, para o autor, se manifesta atualmente com ares de in dubio pro vítima. (CORCOY BIDASOLO, Mirentxu. Expansión del derecho penal y garantías constitucionales. Revista de Derechos Fundamentales, Chile, n. 8, p. 46, 2012).

39 SILVA SÁNCHEZ, Jesús-María. La expansión del derecho penal: aspectos de la política criminal en las sociedades postindustriales. 2. ed. Madrid: Civitas, 2001. p. 25-73.

40 DÍEZ RIPOLLÉS, José Luis. La política criminal en la encrucijada. Buenos Aires: B de F, 2007. p. 108.

41 SILVA SÁNCHEZ, Jesús-María. La expansión del derecho penal: aspectos de la política criminal en las sociedades postindustriales. 2. ed. Madrid: Civitas, 2001. p. 33.

42 DÍEZ RIPOLLÉS, José Luis. La política criminal en la encrucijada. Buenos Aires: B de F, 2007. p. 76. 
43 Entende-se por Direito Penal simbólico a diferença entre as funções as quais a norma penal se declara cumprir e aquelas as quais realmente cumpre, ou seja, conquanto o Direito Penal seja utilizado com a imagem de combate ao crime e como medida de incremento da segurança social (função manifesta ou declarada), apenas se presta (ou se presta predominantemente) ao controle dos sentimentos sociais de insegurança, produzindo momentaneamente uma sensação de segurança (função latente). (HASSEMER, Winfried. Direito penal: fundamentos, estrutura, política. Organização e revisão de Carlos Eduardo de Oliveira. Tradução de Adriana Beckman Meirelles et al. Porto Alegre: Sergio Antonio Fabris, 2008. p. 220-221).

44 HASSEMER, Winfried. Direito penal: fundamentos, estrutura, política. Organização e revisão de Carlos Eduardo de Oliveira. Tradução de Adriana Beckman Meirelles et al. Porto Alegre: Sergio Antonio Fabris, 2008. p. 222.

45 CALlEGARI, André Luís; WERMUTH, Maiquel Ângelo Dezordi. Sistema Penal e Política Criminal. Porto Alegre: Livraria do Advogado, 2010. p. 29.

46 PÉREZ CEPEDA, Ana Isabel. La seguridad como fundamento de la deriva del Derecho penal postmoderno. Madrid: Editora Iustel, 2007. p. 308.

47 BACIGALUPO, Enrique. Derecho penal y el Estado de Derecho. Chile: Editorial Jurídica de Chile, 2005. p. 104.

48 ZAFFARONI, Eugenio Raúl. O inimigo no direito penal. 3. ed. Trad. de Sérgio Lamarão. Rio de Janeiro: Revan, 2011.p. 14.

49 JAKOBS, Günther; CANCIO MELIÁ, Manuel. Direito penal do inimigo: noç̃es e críticas. Organização e tradução de André Luís Callegari e Nereu José Giacomolli. 6. ed. Porto Alegre: Livraria do Advogado, 2012.

50 CALVEIRO, Pilar. Estado, Estado de excepción y violencia. Revista de Ciencias Sociales, Montevidéu, n. 24, ano XXI, p. 96-97, 2008.

51 AGAMBEN, Giorgio. Estado de exceção. Tradução de Iraci D. Poleti. 2. ed. São Paulo: Boitempo, 2004. p. 12-13.

52 ZAFFARONI, Eugenio Raúl. O inimigo no direito penal. 3. ed. Tradução de Sérgio Lamarão. Rio de Janeiro: Revan, 2011. p. 14.

53 CALVEIRO, Pilar. Estado, Estado de excepción y violencia. Revista de Ciencias Sociales, Montevidéu, n. 24, ano XXI, p. 97, 2008.

54 Ibid., p. 98.

55 AGAMBEN, Giorgio. Estado de exceção. Tradução de Iraci D. Poleti. 2. ed. São Paulo: Boitempo, 2004. p. 12-14.

56 MUÑOZ CONDE, Francisco. La generalización del derecho penal de excepción: tendencias legislativas y doctrinales: entre la tolerancia cero y el derecho penal del enemigo. Revista Ciencia Jurídica, Chile, n. 1, ano 1, p. 115, 2011.

57 FERRAJOLI, Luigi. Direito e razão: teoria do garantismo penal. Tradução de Ana Paula Zomer Sica, Fauzi Hassan Choukr, Juarez Tavares e Luiz Flávio Gomes. 3. ed. São Paulo: Revista dos Tribunais, 2010. p. 746.

58 Ibid., p. 747.

59 MUÑOZ CONDE, Francisco. La generalización del derecho penal de excepción: tendencias legislativas y doctrinales: entre la tolerancia cero y el derecho penal del enemigo. Revista Ciencia Jurídica, Chile, ano 1, n. 1, p. 134, 2011.

60 Ibid., p. 127.

61 Adverte-se, com Francisco Muñoz Conde, que não se sabe se Günther Jakobs, defensor do Direito Penal do inimigo, concordaria com um Direito Penal fundamentado unicamente em uma razão de Estado. Contudo, é possível se chegar à defesa da razão de Estado como fundamentação do Direito Penal se utilizando da lógica de distinção entre cidadão e inimigo. (MUÑOZ CONDE, Francisco. La generalización del derecho penal de excepción: tendencias legislativas y doctrinales: entre la tolerancia cero y el derecho penal del enemigo. Revista Ciencia Jurídica, Chile, ano 1, n. 1, p. 135, 2011).

62 MUÑOZ CONDE, Francisco. La generalización del derecho penal de excepción: tendencias legislativas y doctrinales: entre la tolerancia cero y el derecho penal del enemigo. Revista Ciencia Jurídica, Chile, ano 1, n. 1, p. 134, 2011.

63 FERRAJOLI, Luigi. Direito e razão: teoria do garantismo penal. Tradução de Ana Paula Zomer Sica, Fauzi Hassan Choukr, Juarez Tavares e Luiz Flávio Gomes. 3. ed. São Paulo: Revista dos Tribunais, 2010. p. 753.

64 Ibid., p. 753.

65 Ibid., p. 754. 
66 MUÑOZ CONDE, Francisco. La generalización del derecho penal de excepción: tendencias legislativas y doctrinales: entre la tolerancia cero y el derecho penal del enemigo. Revista Ciencia Jurídica, Chile, ano 1, n. 1, p. 139, 2011.

67 FERRAJOLI, Luigi. Direito e razão: teoria do garantismo penal. Tradução de Ana Paula Zomer Sica, Fauzi Hassan Choukr, Juarez Tavares e Luiz Flávio Gomes. 3. ed. São Paulo: Revista dos Tribunais, 2010. p. 767.

\title{
THE CRIMINAL LAW OF THE ENEMY AS AN EXCEPTIONTOTHE RULE OF LAW: THE STATE OF EMERGENCY AS THE ORDINARY SCENARIO
}

\begin{abstract}
Rule of Law is considered as a barrier - not only formal, but also material - to the exercise of the powers of the State, as a real protection of the rights and guarantees of citizens. In Criminal Law, this barrier is even more important, given the danger of excesses in the application of the punitive power of the State. However, some doctrinal proposals are considered to possibly be in contradiction with the logic of creating barriers to the exercise of the power of the Rule of Law, for instance, the Criminal Law of the Enemy. Therefore, this paper aims at developing the basic principles of the Rule of Law, comparing it to the State of emergency, concluding on the incompatibility of the Criminal Law of the Enemy with such State model. For this purpose, the article makes use of bibliographic research to develop each of the topics to be examined. At the end, it is possible conclude that the Criminal Law of the enemy is an exception incompatible with the Rule of Law.
\end{abstract}

Keywords: Rule of Law. State of emergency. Criminal Law of the Enemy.

Submetido: 17 fev. 2016

Artigo convidado. 